\title{
Tanshinone I effectively induces apoptosis in estrogen receptor- positive (MCF-7) and estrogen receptor-negative (MDA-MB-231) breast cancer cells
}

\author{
IRINA TSOY NIZAMUTDINOVA ${ }^{1 *}$, GYEONG WON LEE $^{2 *}$, KUN HO SON $^{3}$, SU JIN JEON ${ }^{3}$, SAM SIK KANG ${ }^{4}$, \\ YEONG SHIK KIM ${ }^{4}$, JAE HEUN LEE ${ }^{1}$, HAN GEUK SEO ${ }^{1}$, KI CHURL CHANG ${ }^{1}$ and HYE JUNG KIM ${ }^{1}$ \\ ${ }^{1}$ Department of Pharmacology, School of Medicine, Institute of Health Sciences, Gyeongsang National University, Jinju; \\ ${ }^{2}$ Department of Internal Medicine, College of Medicine, Gyeongnam Regional Cancer Center, Gyeongsang National \\ University, Jinju; ${ }^{3}$ Department of Food Science and Nutrition, Andong National University, Andong; \\ ${ }^{4}$ Natural Product Research Institute, Seoul National University, Seoul, South Korea
}

Received April 14, 2008; Accepted June 4, 2008

DOI: 10.3892/ijo_00000031

\begin{abstract}
Danshen (Salvia miltiorrhiza Bunge) is a herb that has been widely and successfully used for treating inflammatory diseases in clinics in Asia. The relatively abundant tanshinones, tanshinone I, tanshinone IIA, cryptotanshinone, and dihydrotanshinone, have been isolated from Danshen. These tanshinones are the major diterpenes isolated from Danshen, and show cytotoxic effects on cell lines derived from human carcinomas of the colon, ovary, lung, mouth, and breast. Recently, anti-cancer activities of tanshinone IIA have been reported, which suggest that the structurally similar tanshinone I may possess similar cytotoxic effects on tumor cells. We investigated the effect of tanshinone I on the induction of apoptosis in human breast cancer cells (MCF-7 and MDA-MB-231) in vitro. Tanshinone I inhibited cell proliferation of MCF-7 and MDA-MB-231 cells in a doseand time-dependent manner, as assayed by MTT. In addition, TUNEL assay and flow cytometry showed that tanshinone I significantly induced apoptosis in MCF-7 and MDA-MB-231 cells. The induction of apoptotic cell death was mediated by the activation of caspase 3 , the downregulation of the level of the anti-apoptotic protein, $\mathrm{Bcl}-2$, and the upregulation of the level of the pro-apoptotic protein, Bax. Taken together, these results reveal a potential mechanism for the anti-cancer effect of tanshinone I on human breast cancer cells, and suggest
\end{abstract}

Correspondence to: Dr Hye Jung Kim or Dr Ki Churl Chang Department of Pharmacology, College of Medicine, Gyeongsang National University, 92 Chilam-dong, Jinju, South Korea

E-mail: hyejungkim@gnu.ac.kr

E-mail: kcchang@gsnu.ac.kr

${ }^{*}$ Contributed equally

Key words: apoptosis, Bax, Bcl-2, breast cancer, caspase-3, tanshinone I that tanshinone I may serve as an effective adjunctive reagent in the treatment of human breast cancer.

\section{Introduction}

Danshen (Salvia miltiorrhiza Bunge) is a herb that has been widely used in traditional Chinese medicine for treating coronary heart diseases, such as angina pectoris and myocardial infarction. Along with more than 20 phenolic acids, about 30 diterpene compounds (including the relatively abundant tanshinones, tanshinone I, tanshinone IIA, cryptotanshinone, and dihydrotanshinone) have been isolated from Danshen (1). These abundant tanshinones are the major diterpenes isolated from Danshen, and show cytotoxic effects on cell lines derived from human carcinomas of the colon, ovary, lung, mouth, and breast (2-4). Recently, the anti-cancer activities of tanshinone IIA were reported (4-6). Another tanshinone, tanshinone I, is structurally similar to tanshinone IIA, and may possess similar cytotoxic effects on tumor cells. Our preliminary studies indicated that tanshinone I exhibits the strongest inhibitory effect on TNF- $\alpha$-induced adhesion molecules in endothelial cells, which are important in the development of cancer metastasis (unpublished data). However, the effect of tanshinone I on cancer cells and its mechanisms of action are not yet understood.

Breast cancer is one of the most common malignancies in women, and is the leading cause of death worldwide for women between the ages of 40 and 55 (7). The diagnosis of breast cancer falls into two broad categories, either estrogen receptor (ER)-positive or ER-negative, based on the level of ER in the cancer cells (8). ER is expressed in about $60 \%$ of all breast cancers. ER-positive breast cancer generally has a better prognosis, and is often responsive to antiestrogen therapy. In contrast, ER-independent breast cancers are more aggressive and unresponsive to antiestrogens (9). Breast cancer is currently controlled by surgery and radiotherapy, and frequently supported by adjuvant chemo- or hormonotherapies. Given the fact that breast cancer is highly resistant to chemotherapy (10), there is a great need for the 


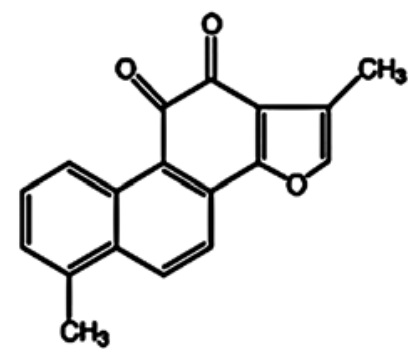

Figure 1. Chemical structure of tanshinone I extracted from Danshen (Salvia miltiorhiza).

development of new therapeutic drugs that are more efficient, or will synergize with the existing drugs. Moreover, there is still no effective cure for patients with advanced stages of the disease, especially in cases of hormone-independent cancers $(10,11)$. In this study, we investigated the anti-carcinogenic effect of tanshinone I, using MCF-7 cells as an in vitro model for ER-positive breast cancer, and MDA-MB-231 cells as an in vitro model of ER-negative breast cancer.

Recently, the relationship between apoptosis and cancer has been emphasized, with increasing evidence suggesting that the related processes of neoplastic transformation, progression, and metastasis involve the alteration of normal apoptotic pathways (12). The activation of apoptosis contributes to the suppression of malignant transformation, and has been characterized as a fundamental cellular activity for preventing neoplastic development by eliminating genetically damaged cells, or cells that have been improperly induced to divide by a mitotic stimulus $(13,14)$. Thus, induction of apoptosis in cancer cells has become an indicator of the cancer treatment response and reduction of mortality in patients. The Bcl-2 protein family constitutes pro-apoptotic and antiapoptotic regulators of apoptosis. The $\mathrm{Bcl}-2$ protein binds to the pro-apoptotic protein, Bax, to form heterodimers, and the molar ratio of Bax and Bcl-2 determines whether apoptosis is induced or inhibited in the targeted tissues (15). Bax controls cell death through its participation in the disruption of mitochondria, and the subsequent release of cytochrome $c$ in the cytosol (16). Cytochrome c leads to the activation of caspase-3, which is a key mediator of apoptosis (17-20). Several chemotherapeutic and chemopreventive agents have been shown to cause apoptotic cell death through the activation of caspases $(21,22)$.

This study aimed to examine the effect of tanshinone I on cancer cell growth and apoptosis induction in 2 human breast cancer cell lines, MCF-7 and MDA-MB-231.

\section{Materials and methods}

Materials. Tanshinone I was isolated and identified as described previously (23) (Fig. 1). Tanshinone I purity ( $\geq 99 \%$ ) was validated by HPLC. Tissue culture medium RPMI-1640, fetal bovine serum (FBS), and antibiotics (penicillin/streptomycin) were supplied by Gibco-BRL (Rockville, MD). Anti-Bax and anti-Bcl-2 antibodies were purchased from Santa Cruz Biotechnology (Santa Cruz, CA); cleaved form of caspase-3 antibody was obtained from Cell Signaling Technology (Beverly, MA). Enhanced chemiluminescence
(ECL) Western blotting detection reagent was from Amersham (Buckinghamshire, UK). All other chemicals were supplied by Sigma-Aldrich (St. Louis, MO).

Cell culture. MCF-7 and MDA-MB-231 human breast cancer cells with high tumorigenic properties in nude mice were obtained from American Type Culture Collection (ATCC, Manassas, VA), and grown in RPMI-1640 supplemented with 10\% FBS, $2 \mathrm{mM}$ L-glutamine, $25 \mathrm{mM}$ HEPES, $25 \mathrm{mM}$ $\mathrm{NaHCO}_{3}, 100 \mathrm{IU} / \mathrm{ml}$ penicillin, and $10 \mu \mathrm{g} / \mathrm{ml}$ streptomycin.

Cell viability assay. Cell viability was determined colorimetrically using the MTT reagent. Cells at the exponential phase were seeded at $10^{4}$ cells/well in 24-well plates. After different treatments, $20 \mu \mathrm{l}$ of $5 \mathrm{mg} / \mathrm{ml}$ MTT solution was added to each well $(0.1 \mathrm{mg} / \mathrm{ml})$ and incubated for $4 \mathrm{~h}$. The supernatants were aspirated and the formazan crystals in each well were dissolved in $200 \mu 1$ dimethyl sulfoxide (DMSO) for $30 \mathrm{~min}$ at $37^{\circ} \mathrm{C}$, and $570 \mathrm{~nm}$ was read on the Microplate Reader (Bio-Rad, Hercules, CA).

Western blot analysis. For the isolation of total cell extracts, cells were lysed in PRO-PREP protein extract solution. The sample was centrifuged at $13,000 \mathrm{rpm} \times 20 \mathrm{~min}$ at $4^{\circ} \mathrm{C}$. Protein concentration was determined by the Bradford method. An equal volume of $2 \mathrm{X}$ SDS sample buffer $(0.1 \mathrm{M}$ Tris-Cl, $20 \%$ glycerol, $4 \%$ SDS, and $0.01 \%$ bromophenol blue) was added to an aliquot of the supernatant fraction from the lysates and the samples were boiled for $5 \mathrm{~min}$. Aliquots of $30 \mu \mathrm{g}$ of protein were subjected to $10 \%$ SDS-polyacrylamide gel electrophoresis for $1 \mathrm{~h}$ and $30 \mathrm{~min}$ at $110 \mathrm{~V}$. The separated proteins were transferred to a PVDF membrane for $2 \mathrm{~h}$ at $20 \mathrm{~mA}$ with an SD Semi-dry Transfer Cell (Bio-Rad). The membranes were blocked with 5\% non-fat milk in Tris-buffed saline (TBS) containing 0.05\% Tween-20 (TBS-T) for $2 \mathrm{~h}$ at room temperature. Subsequently, the membranes were incubated overnight at $4^{\circ} \mathrm{C}$ with anti-Bax, anti-Bcl-2, and anti-cleaved caspase- 3 antibodies at a concentration of 1:500 $(4 \mu \mathrm{g} / \mathrm{ml})$ in $5 \%$ skim-milk in TBS-T. Bound antibodies were detected by horseradish peroxidase-conjugated anti-rabbit IgG. The membranes were washed and then developed using a Western blotting Luminol Reagent system (Amersham).

Identification of apoptosis by flow cytometry analysis $(F A C S)$. For the analysis of apoptosis using FACS, $1.5 \times 10^{6}$ cells/100-mm culture dish were treated with tanshinone I in a dose- and time-dependent manner, fixed in $70 \%(\mathrm{v} / \mathrm{v})$ ethanol at $-70^{\circ} \mathrm{C}$ for $1 \mathrm{~h}$, then washed twice with cold PBS and resuspended in propidium iodide staining solution $(5 \mu \mathrm{g} / \mathrm{ml}$ propidium iodide, $0.7 \mu \mathrm{g} / \mathrm{ml}$ ribonuclease A, $10 \mathrm{mM}$ Tris $\mathrm{pH} 7.0,1 \mathrm{mM} \mathrm{NaCl}$, and 0.1\% NP-40). Following incubation in the dark for $30 \mathrm{~min}$ at room temperature, cellular DNA was measured to determine cell cycle profiles, using a FACS Calibur $^{\circledR}$ (Becton-Dickinson Biosciences, Franklin Lakes, NJ) and CellQuest ${ }^{\circledR}$ software. At least 20,000 cells were analyzed from each sample and the presence of a sub- $\mathrm{G}_{1}$ compartment indicated apoptosis.

Terminal deoxynucleotidyl transferase-mediated dUTP nickend labeling (TUNEL) assay. MCF-7 and MDA-MB-231 

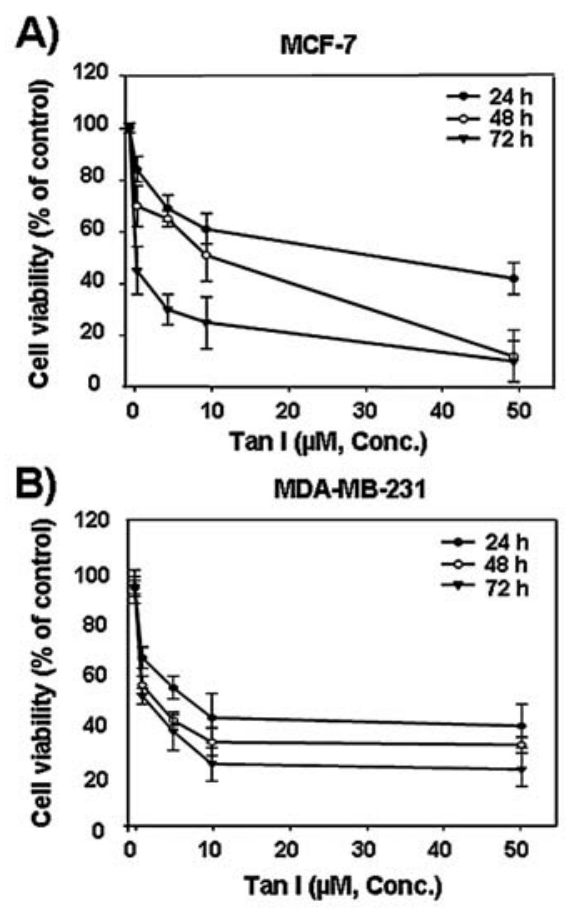

Figure 2. Tanshinone I suppresses cell viabilities of MCF-7 and MDA-MB231 cells. The effect of tanshinone I on cell viability was measured in a concentration- and time-dependent manner by MTT. (A) MCF-7 and (B) MDA-MB-231 cells were incubated with tanshinone I for 24, 48 and $72 \mathrm{~h}$. It was clearly observed that tanshinone I significantly decreased cell viabilities of both cell lines in a concentration- and time-dependent manner. The data represents the mean \pm SD of 3 separate experiments performed in triplicate.

cells were seeded on coverslips in a 6-well plate until $80 \%$ confluent, followed by treatment with tanshinone I for $24 \mathrm{~h}$ at the indicated doses $(1,5,10$ and $50 \mu \mathrm{M})$. Cells were subsequently washed twice with PBS and fixed with $4 \%$ paraformaldehyde in PBS overnight at $4^{\circ} \mathrm{C}$. Fixed cells were washed with $0.1 \%$ Tween-20 in PBS (PBS-T), and permeabilized for $90 \mathrm{~min}$ at $37^{\circ} \mathrm{C}$ in PBS containing $0.5 \%$ Triton X-100. Apoptotic cells were determined using an In Situ Cell Death Detection Kit (Roche Applied Science, Penzberg, Germany). After staining, cells were washed for 5 min in PBS-T three times, and observed using a confocal laser scanning microscope. TUNEL-positive cells were photographed in four or more randomly chosen fields.

Statistical evaluations. Scanning densitometry was performed using an Image Master ${ }^{\circledR}$ VDS (Pharmacia Biotech Inc., San Francisco, CA). Treatment groups were compared using one-way analysis of variance (ANOVA), and the NewmanKeuls test was used to detect any significant differences identified in the ANOVA. $\mathrm{P}<0.05$ or $\mathrm{P}<0.01$ was accepted as significant.

\section{Results}

Tanshinone I induces cell death in MCF-7 and MDA-MB-23I breast cancer cells, in a dose-and time-dependent manner. In order to examine cell viabilities of MCF-7 and MDAMB-231 cells in response to tanshinone I, cells were dose-

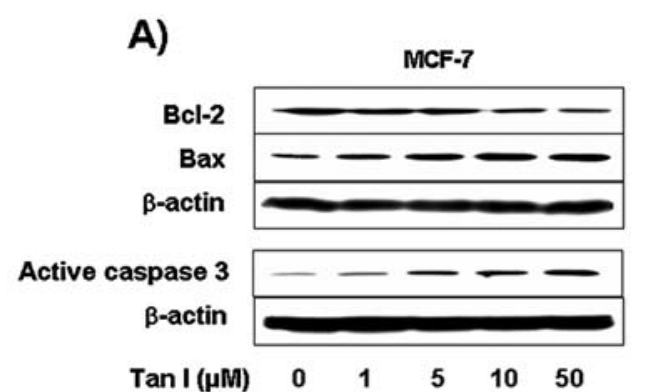

B)

MDA-MB-231

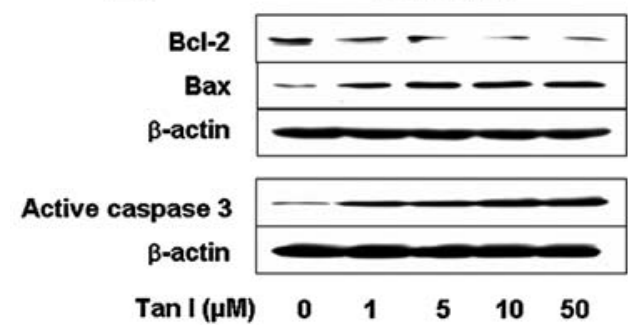

Figure 3. Tanshinone I activates the caspase-3 pathway and decreases the $\mathrm{Bcl}-2 / \mathrm{Bax}$ ratio in breast cancer cells. Cells were treated with tanshinone I in a concentration-dependent manner for 4 and $6 \mathrm{~h}$ as described in Materials and methods, and total proteins were extracted. The levels of Bcl-2, Bax, and cleaved form of caspase-3 were determined in MCF-7 (A) and MDAMB-231 (B) cells by Western blot analysis. These data were confirmed by 3 independent experiments.

dependently treated with tanshinone I for 24,48 and $72 \mathrm{~h}$. As shown in Fig. 2, $50 \mu \mathrm{M}$ tanshinone I markedly suppressed cell viability at $24 \mathrm{~h}$ in MCF-7 cells as well as in MDA-MB231 cells. However, with increasing incubation times, even low doses of tanshinone I significantly decreased cell viability. Incubation with tanshinone I $(50 \mu \mathrm{M})$ for $72 \mathrm{~h}$ decreased cell viability by about $92 \%$ in MCF-7 cells, and $79 \%$ in MDA-MB-231 cells. Tanshinone I induced cytotoxicity more effectively in MDA-MB-231 cells than in MCF-7 cells at low doses $(1$ or $5 \mu \mathrm{M})$ and at 24 -h or 48 -h treatment.

Tanshinone I induces apoptotic cell death by decreasing the Bcl-2/Bax ratio and activating cleavage of caspase-3 in breast cancer cells. To examine if tanshinone I-induced cytotoxicity was due to the induction of apoptotic cell death in both breast cancer cell lines, the levels of the apoptosisassociated proteins, Bcl-2, Bax, and cleaved caspase-3, were detected by Western blot analysis. Since tanshinone I induced maximum levels of Bcl-2 and Bax at 4-h treatment and cleaved form of caspase-3 at 6-h treatment in MCF-7 and MDA-MB-231 cells (data not shown), the cells were treated in a dose-dependent manner with tanshinone $\mathrm{I}$ for $4 \mathrm{~h}$ to detect Bcl-2 and Bax, or for $6 \mathrm{~h}$ to detect the cleaved form of caspase-3. Western blot analysis showed that tanshinone I dose-dependently increased pro-apoptotic Bax protein levels and decreased anti-apoptotic Bcl-2 levels in parallel in MCF-7 and MDA-MB-231 cells (Fig. 3). In addition, tanshinone I dose-dependently increased the levels of cleaved caspase- 3 in both breast cancer cell lines (Fig. 3). Interestingly, similar to Fig. 2, low dose tanshinone I ( 1 or $5 \mu \mathrm{M})$ more effectively induced the cleaved form of caspase- 3 in MDA-MB-231 

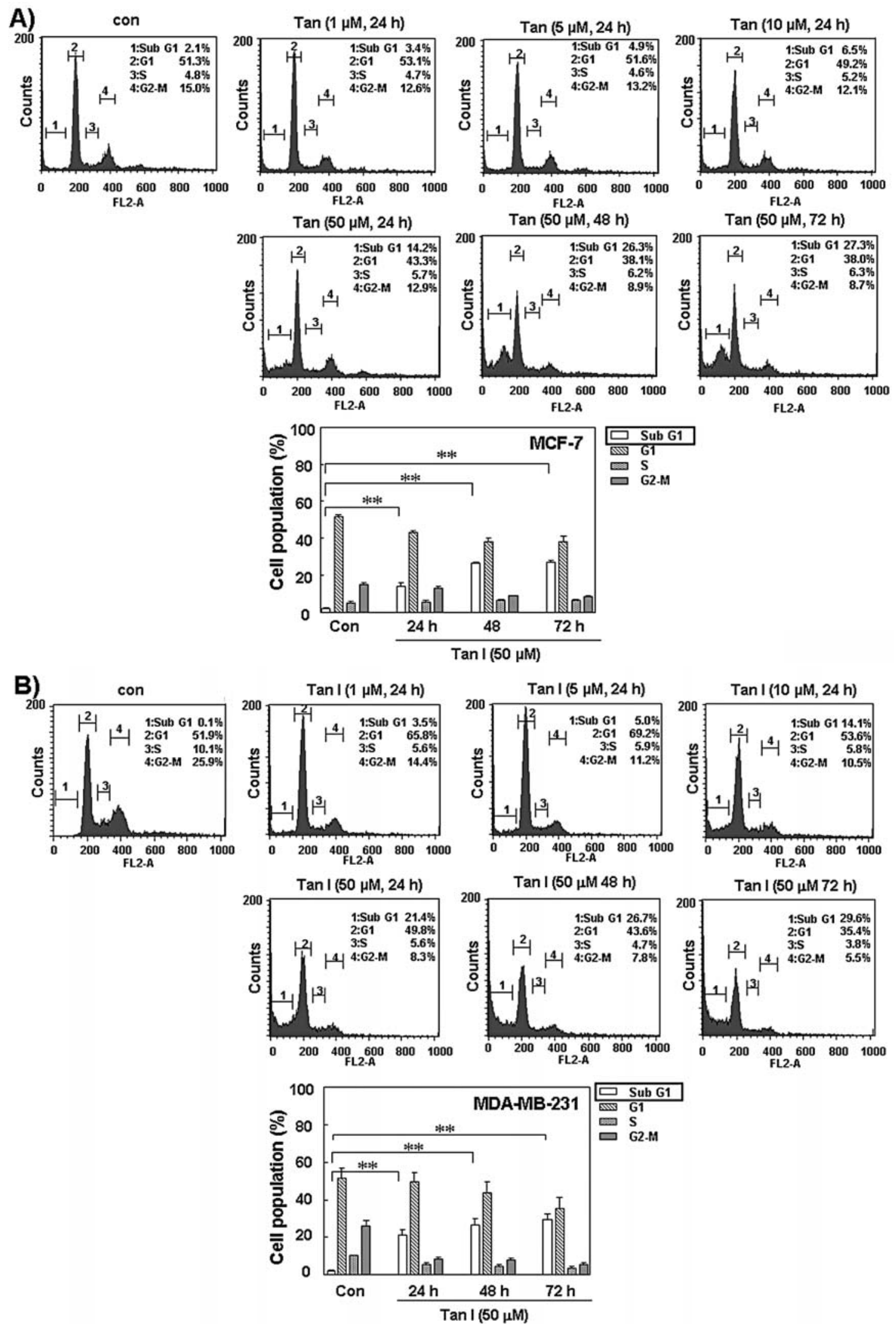

Figure 4. Flow cytometry analysis of tanshinone I-treated MCF-7 (A) and MDA-MB-231 (B) cells. Cells were exposed to various concentrations of tanshinone I for 24, 48 and $72 \mathrm{~h}$. The treated cells were harvested, stained with propidium iodide, and examined by FACS analysis. Cell cycle was presented as a percentage of cell population at each dose at $24 \mathrm{~h}$, and time-dependently at a high dose $(50 \mu \mathrm{M})$. The data represent the mean $\pm \mathrm{SD}$ of three separate experiments performed in triplicate. One-way analysis of variance was used to compare the multiple group means followed by Newman-Keuls test (significance compared to control, ${ }^{* *} \mathrm{P}<0.01$ ).

cells. These results show that tanshinone I induces apoptotic cell death in breast cancer cells through the downregulation of the $\mathrm{Bcl}-2 / \mathrm{Bax}$ ratio, and the upregulation of caspase- 3 cleavage. 
A)
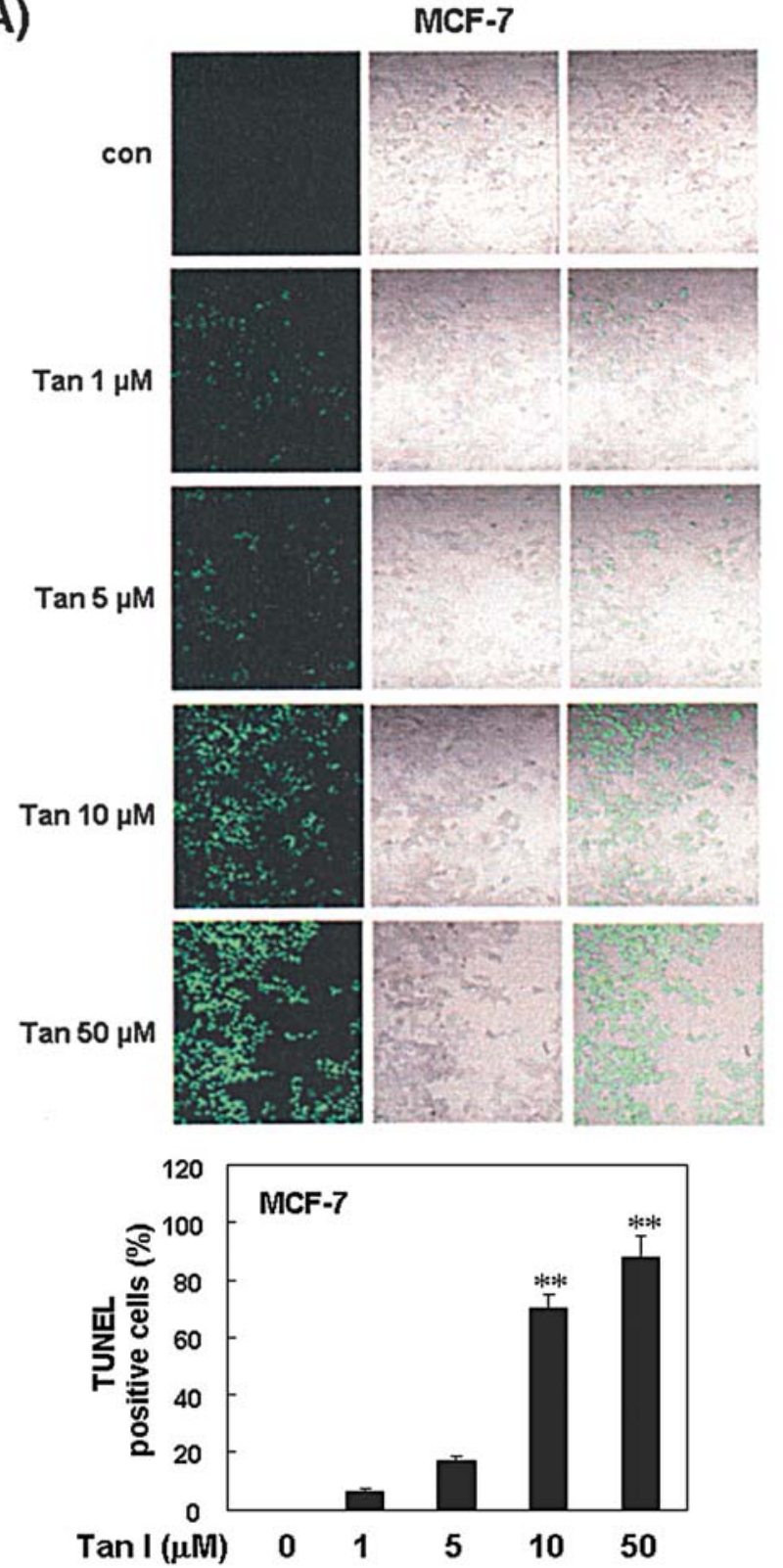

B)
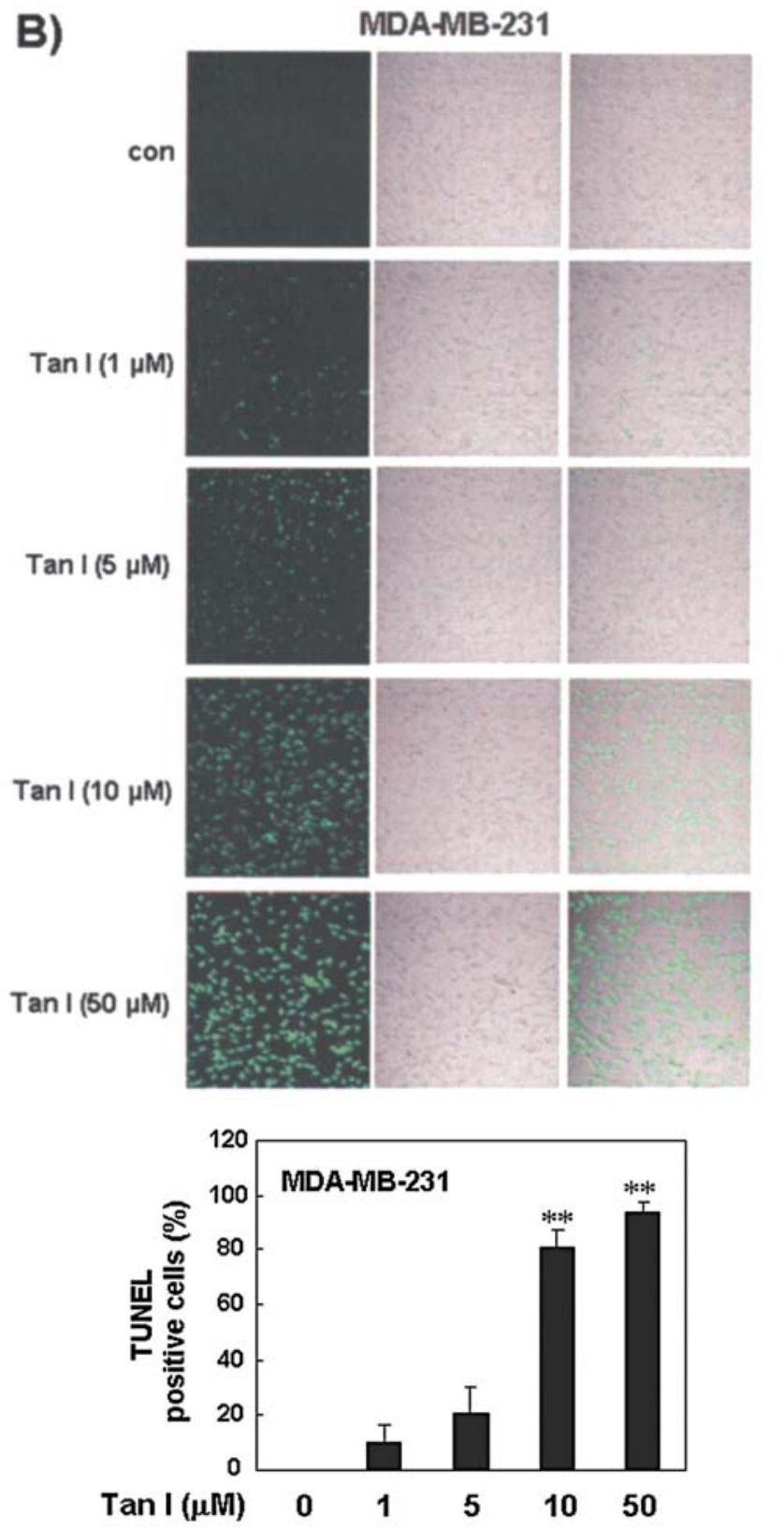

Figure 5. Tanshinone I-induced apoptotic cell death as shown by TUNEL assay. Representative micrographs of TUNEL staining of cancer cells are shown after cells were treated with or without tanshinone I in a dose-dependent manner $(1,5,10$ and $50 \mu \mathrm{M})$ for 24 h. Tanshinone I significantly increased the positive nuclei (green) in MCF-7 (A) as well as MDA-MB-231 cells (B). Data were confirmed by 3 independent experiments. One-way analysis of variance was used to compare the multiple group means by Newman-Keuls test (significance compared to control, ${ }^{* *} \mathrm{P}<0.01$ ).

Tanshinone I induces apoptotic cell death in breast cancer cells as shown by FACS analysis. Next, we performed flow cytometry to confirm whether tanshinone I could induce cell apoptosis in a dose- $(1,5,10$ and $50 \mu \mathrm{M})$ and time- $(24$, 48 and $72 \mathrm{~h}$ ) dependent manner. As shown in Fig. 4A, the apoptotic cell population (sub- $\mathrm{G}_{1}$ ) was markedly increased as the concentration and incubation time of tanshinone I was increased in MCF-7 cells. FACS analysis indicated that $50 \mu \mathrm{M}$ tanshinone $\mathrm{I}$ increased the apoptotic cell population by 14,26 and $27 \%$ at 24,48 and $72 \mathrm{~h}$, respectively. A similar effect of tanshinone I was observed in MDA-MB-231 cells (Fig. 4B). The effect of tanshinone I on MDA-MB-231 cells was more significant compared with that of MCF-7 cells; tanshinone I at $50 \mu \mathrm{M}$ induced apoptotic cell populations of 21,26 and $29 \%$ at 24,48 and 72 h, respectively, and 24-h treatment of tanshinone I induced apoptotic cell death by $14.1 \%$ compared to $6.5 \%$ in MCF-7 cells (Fig. 4B). However, it is not clear from these results where in the cell cycle tanshinone I arrested these cells.

Tanshinone I induces apoptotic cell death in breast cancer cells as shown by TUNEL assay. TUNEL assay also showed that the number of TUNEL-positive cells induced by tanshinone I at 24 h-treatment was significantly increased as the concentration of tanshinone I was elevated in MCF-7 and MDA-MB-231 cells (Fig. 5). The results indicate that even low concentrations of tanshinone I ( 1 and $5 \mu \mathrm{M})$ showed apoptosis-inducing effects, and at high doses (10 and $50 \mu \mathrm{M})$, the fraction of apoptotic cell bodies was markedly increased by tanshinone I. In summary, the data indicate that 
tanshinone I effectively induces apoptosis in both breast cancer cell lines.

\section{Discussion}

Breast cancer is the most common neoplasm in women of both developed and developing countries (7). The human breast cancer cell line, MCF-7, is ER-positive, but approximately one-third of breast cancers are ER-negative, with the latter carrying a worse prognosis $(9,24)$. Therefore, it is important to identify new agents that are effective in both ER-positive and -negative breast cancers. Our results demonstrate that tanshinone I not only has a powerful inhibitory effect on the proliferation of ER-positive human breast cancer cells, but also significantly inhibits the growth of human ER-negative cells in vitro. In this study, we found for the first time that tanshinone I has potential anti-cancer activities in the human breast cancer cell lines, MCF-7 (ER-positive) and MDA-MB-231 (ER-negative), and appears to exert this anti-cancer effect by inhibiting proliferation and inducing apoptotic cell death.

The mitochondrial apoptotic pathway has been described as an important mediator of apoptotic cell death in mammalian cells (25). The induction of apoptosis protects organisms against neoplastic development $(13,14)$. Many genes have been reported to be linked with the regulation of programmed cell death under physiological and pathological conditions, including the Bcl-2 and Bax genes, which are believed to have a major role in determining a cell's survival or death after apoptotic stimuli. Bax is normally found as a monomer in the cytosol of non-apoptotic cells. In response to apoptotic stimuli, Bax oligomerizes and translocates to the outer mitochondrial membrane (26), where it induces mitochondrial membrane permeabilization (27) and cytochrome $c$ release (28). Overexpression of the anti-apoptotic protein, Bcl-2, has been found to stabilize the outer membrane and prevent the release of cytochrome $c$ following a variety of insults. In this study, tanshinone I dramatically increased the level of the pro-apoptotic protein, Bax, and significantly decreased the level of anti-apoptotic protein, Bcl-2, in both MCF-7 and MDA-MB-231 breast cancer cell lines (Fig. 3). In concert with these changes, caspase- 3 activation was induced by tanshinone I in a dose-dependent manner (Fig. 3). It has been reported that the ratio of anti-apoptotic proteins to proapoptotic proteins is more important than the actual protein levels in determining whether apoptosis will proceed (29). Thus, it is reasonable to suggest that the apoptotic potential of tanshinone $\mathrm{I}$ is directly related to its ability to alter the ratio of pro-apoptotic proteins to anti-apoptotic proteins in targeted cells.

Tanshinone I also showed an inhibitory effect on cell viability in MCF-7 and MDA-MB-231 cells. To determine whether cell death was due to the induction of apoptosis, FACS analysis and the TUNEL assay were performed. The induction of apoptosis and/or the inhibition of cell proliferation is highly correlated with the activation of a variety of intracellular signaling pathways to arrest the cell cycle in the $G_{0}$, $\mathrm{G}_{1}, \mathrm{~S}$, or $\mathrm{G}_{2}-\mathrm{M}$ phases. From our results, it is not easy to determine which checkpoint tanshinone I targets. However, because tanshinone I significantly increased the sub- $G_{1}$ phase cell population in both cell lines, we speculate that tanshinone I may arrest cells in the $\mathrm{G}_{0}-\mathrm{G}_{1}$ phase in a timedependent manner. Additionally, the TUNEL assay showed an increased number of apoptotic bodies in the cells after treatment with tanshinone $I$ in a concentration-dependent manner. Thus, it is clear that tanshinone I has the ability to induce apoptosis in breast cancer cells.

In conclusion, this study determined an anti-cancer effect of tanshinone I mediated by the induction of apoptosis, which is associated with caspase- 3 activation and the altered ratio between Bcl-2 and Bax protein levels, in MCF-7 and MDAMB-231 cells. As apoptosis has become a new therapeutic target in cancer research, these results confirm the potential of tanshinone I as an agent of chemotherapeutic and cytostatic activity in human breast cancer cells. However, further investigation of its activity in vivo is necessary to elaborate on and exploit this nascent promise.

\section{Acknowledgements}

This work was supported by Korea Food and Drug Administration (S-06-02-2-CHM-230-0-C) and by the MRC program of MOST/KOSEF (R13-2005-012-01003-0).

\section{References}

1 Zhou L, Zhong Z and Chow MS: Danshen: an overview of its chemistry, pharmacology, pharmacokinetics and clinical use. J Clin Pharmacol 45: 1345-1359, 2005.

$2 \mathrm{Wu}$ WL, Chang WL and Chen CF: Cytotoxic activities of tanshinones against human carcinoma cell lines. Am J Chin Med 19: 207-216, 1991.

3 Ryu SY, Lee CO and Choi SU: In vitro cytotoxicity of tanshinones from Salivia miltiorrhiza. Planta Med 63: 339-342, 1997.

4 Wang X, Wei Y, Yuan S, Liu G, Lu Y, Zhang J and Wang W: Potential anticancer activity of tanshinone IIA against human breast cancer. Int J Cancer 116: 799-807, 2005.

5. Liu JJ, Lin DJ, Liu PQ, Huang M, Li XD and Huang RW: Induction of apoptosis and inhibition of cell adhesive and invasive effects by tanshinone IIA in acute promyelocytic leukemia cells in vitro. J Biomed Sci 13: 813-823, 2006.

6. Wang J, Wang X, Jiang S, Yuan S, Lin P, Zhang J, Lu Y, Wang Q, Xiong Z, Wu Y, Ren J and Yang H: Growth inhibition and induction of apoptosis and differentiation of tanshinone IIA in human glioma cells. J Neurooncol 82: 11-21, 2007.

7. Baselga J and Mendelsohn J: The epidermal growth factor receptor as a target for therapy in breast carcinoma. Breast Cancer Res Treat 29: 127-138, 1994.

8. Jensen EV: Hormone dependency of breast cancer. Cancer 47: 2319-2326, 1981.

9. Anandappa SY, Sibson R, Platt-Higgins A, Winstanley JH, Rudland PS and Barraclough R: Variant estrogen receptor $\alpha$ mRNAs in human breast cancer specimens. Int $\mathrm{J}$ Cancer 88 : 209-216, 2000.

10. Banger J, Zwick E and Ullrich A: Molecular targets for breast cancer therapy and prevention. Nat Med 7: 548-552, 2001.

11. Roy AM, Baliga MS and Katiyar SK: Epigallocatechin-3gallate induces apoptosis in estrogen receptor-negative human breast carcinoma cells via modulation in protein expression of p53 and Bax and caspase-3 activation. Mol Cancer Ther 4: 81-90, 2005.

12. Bold RJ, Termuhlen PM and McConkey DJ: Apoptosis, cancer and cancer therapy. Surg Oncol 6: 133-142, 1997.

13. Hickman JA: Apoptosis induced by anticancer drugs. Cancer Metastasis Rev 11: 121-129, 1992.

14. Barry MA, Behnke CA and Eastman A: Activation of programmed cell death (apoptosis) by cisplatin, other anticancer drugs, toxins and hyperthermia. Biochem Pharmacol 40: 2353-2362, 1990 .

15. Oltvai ZN, Milliman CL and Korsmeyer SJ: Bcl-2 heterodimerizies in vivo with a conserved homolog, Bax, that accelerates programmed cell death. Cell 74: 609-619, 1993. 
16. Marzo I, Brenner C, Zamzami N, Jurgensmeier JM, Susin SA, Vieira HL, Prevost MC, Xie Z, Matsuyama S, Reed JC and Kroemer G: Bax and adenine nucleotide translocator cooperate in the mitochondrial control of apoptosis. Science 281: 2027-2031, 1998.

17. Yang J, Liu X, Bhalla K, Kim CN, Ibrado AM, Cai J, Peng TI, Jones DP and Wang X: Prevention of apoptosis by Bcl-2: release of cytochrome $\mathrm{c}$ from mitochondria blocked. Science 275: 1129-1132, 1997.

18. Kluck RM, Bossy-Wetzel E, Green DR and Newmeyer DD: The release of cytochrome $\mathrm{c}$ from mitochondria: a primary site for Bcl-2 regulation of apoptosis. Science 275: 1132-1136, 1997.

19. Reed JC: Regulation of apoptosis by Bcl-2 family proteins and its role in cancer and chemotheresistance. Curr Opin Oncol 7: 541-546, 1995.

20. Communal C, Sumandea M, de Tombe P, Narula J, Solaro RJ and Hajjar RJ: Functional consequences of canspase activation in cardiac myocytes. Proc Natl Acad Sci USA 99: 6252-6256, 2002.

21. Eamshaw WC, Martins LM and Kaufmann SH: Mammalian caspase: structure, activation, substrates, and functions during apoptosis. Annu Rev Biochem 68: 383-424, 1999.

22. Esposi MD: The roles of Bid. Apoptosis 7: 433-440, 2002.
23. Kim DH, Jeon SJ, Jung JW, Lee S, Yoon BH, Shin BY, Son KH, Cheong JH, KimYS, Kang SS, Ko KH and Ryu JH: Tanshinone congeners improve memory impairments induced by scopolamine on passive avoidance tasks in mice. Eur $\mathrm{J}$ Pharmacol 574: 140-147, 2007.

24. Swami S, Raghavachari N, Muller UR, Bao YP and Feldman D: Vitamin D growth inhibition of breast cancer cells: gene expression patterns assessed by cDNA microarray. Breast Cancer Res Treat 80: 49-62, 2003.

25. Hengartner MO: The biochemistry of apoptosis. Nature 407: 770-776, 2000.

26. Goping IS, Gross A, Lavoie JN, Nguyen M, Jemmerson R, Roth K, Korsmeyer SJ and Shore GC: Regulation targeting of BAX to mitochondria. J Cell Biol 143: 207-215, 1998.

27. Kuwana $T$ and Newmeyer DD: Bcl-2 family proteins and the role of mitochondria in apoptosis. Curr Opin Cell Biol 15: 691-699, 2003.

28. Wei MC, Zong WX, Cheng EH, Lindsten T, Panoutsakopoulou V, Ross AJ, Roth KA, MacGregor GR, Thompson CB and Koresmeyer SJ: Proapoptotic BAX and BAK: a requisite gateway to mitochondrial dysfunction and death. Science 292: 727-730, 2001.

29. Chao DT and Korsmeyer SJ: Bcl-2 family: regulators of cell death. Annu Rev Immunol 16: 395-419, 1998. 